\title{
O CUIDADO FAMILIAR E SOCIAL NA PROMOÇÃO DA SAÚDE DA CRIANÇA VÍTIMA DE VIOLÊNCIA DOMÉSTICA
}

Bruna Rafaele Milhorini Greinert', Andréa Grano Marques ${ }^{2}$, Rute Grossi Milani $^{3}$

1 Psicóloga, mestre em Promoção da saúde e professora do curso de psicologia do Centro Universitário Cesumar - UniCesumar - Maringá - Pr, Brasil. (brunamilhorini@hotmail.com).

2 Profa Dra do Programa de Mestrado em Promoção da Saúde do Centro Universitário Cesumar - Unicesumar - Maringá, Pr, Brasil. Pesquisadora do Instituto

Cesumar de Ciência, Tecnologia e Inovação (ICETI)

3 Profa Dra do Programa de Mestrado em Promoção da Saúde e do Programa de Mestrado em Tecnologias Limpas do Centro Universitário Cesumar UniCesumar - Maringá - Pr, Brasil; Pesquisadora do Instituto Cesumar de Ciência, Tecnologia e Inovação (ICETI)

Recebido em: 06/04/2018 - Aprovado em: 10/06/2018 - Publicado em: 20/06/2018 DOI: 10.18677/EnciBio_2018A102

\begin{abstract}
RESUMO
Objetivou-se neste artigo refletir sobre o impacto da violência doméstica ao desenvolvimento infantil e analisar de que forma o cuidado familiar e as ações do governo podem atuar como medidas de proteção e promoção da saúde e bem-estar da criança. Trata-se de um estudo teórico. Os estudos foram selecionados por meio de bases de dados eletrônicas, tais como: LILACS, Scielo e BVS-PSI. Na análise dos artigos verificou-se que a violência infantil encontra-se associada a condições precárias de vida, como desemprego e baixa renda e que as crianças apresentam prejuízos em áreas comportamentais, emocionais e sociais. $\mathrm{O}$ desenvolvimento infantil saudável está interligado à vinculação satisfatória nas relações familiares, ou seja, o cuidado dos pais à criança favorece a promoção de sua saúde e bem-estar.
\end{abstract}

PALAVRAS-CHAVE: Bem-estar, maus-tratos, negligência, qualidade de vida.

\section{THE FAMILY AND SOCIAL CARE IN THE PROMOTION OF THE HEALTH OF THE VICTIM CHILD OF DOMESTIC VIOLENCE}

\begin{abstract}
The objective of this article was to reflect on the impact of domestic violence on child development and to analyze how family care and government actions can act as measures to protect and promote the health and well-being of the child. This is a theoretical study with narrative review. The studies were selected through electronic databases, such as: LILACS, Scielo and BVS-PSI. In the analysis of the articles it was verified that child violence is associated with precarious conditions of life, such as unemployment and low income, and that children present losses in behavioral, emotional and social areas. Healthy child development is intertwined with satisfactory linkage in family relationships, that is, parenting the child favors the promotion of their health and well-being.
\end{abstract}

KEYWORDS: Maltreatment, negligence, welfare, quality of life. 


\section{INTRODUÇÃO}

Por ocorrer no próprio espaço do lar, a violência doméstica coloca a família como ponto central do problema, pois seus integrantes encontram-se ao mesmo tempo em condição de vítima e de agressores. Nesse contexto da violência, a infância é um dos períodos mais vulneráveis, por sua inocência e imaturidade. $O$ fato de a criança ter seus direitos violados por aqueles que deveriam protegê-la, pode resultar em sequelas em seu desenvolvimento que se estenderão por toda a vida (XIMENES NETO et al., 2013). De acordo com a Organização Mundial da Saúde (2006), a violência infantil classifica-se em quatro tipos: física, sexual, psicológica e negligência.

A violência física configura-se quando um indivíduo faz uso de força física, de algum tipo de instrumento ou arma que possa causar lesões no corpo da vítima. A violência psicológica refere-se a toda ação que atinge de forma negativa a autoestima, a identidade ou o desenvolvimento do outro. A negligência, por sua vez, caracteriza-se pela omissão de responsabilidade de um ou mais membros da família em relação a outro, principalmente aos que necessitam de ajuda, seja por conta da idade ou condição física. Por fim, a violência sexual é evidenciada quando uma pessoa obriga outra a realizar práticas sexuais, seja por meio de força física, uso de armas ou drogas e influência psicológica (DAY et al., 2003). Ainda que tais classificações da violência existam teoricamente separadas, é necessário salientar que na prática estão interligadas de diversas maneiras.

A violência caracteriza-se como um forte estressor no processo normal de crescimento e amadurecimento infantil, visto que a criança encontra-se em condições peculiares de seu desenvolvimento, as quais propiciam extrema dependência dos pais, cuidadores e familiares (NUNES; SALES, 2016). O contexto familiar em que a violência doméstica é vivenciada, ao invés de proporcionar a seus membros um ambiente acolhedor e que possibilite o desenvolvimento saudável de relações, caracteriza-se pela falta de recursos para lidar com situações cotidianas, opressões, estresse e condições precárias de vida (APOSTÓLICO et al. 2012).

De acordo com Almeida et al. (2013), a violência contra a criança pode acontecer de forma direta e indireta, ou seja, se manifestar especificamente com a criança, ou ser presenciada, no caso da agressão sofrida por outro integrante da família. Porém, ressalta-se que ambos os casos podem ocasionar prejuízos à saúde física e mental da criança.

Mediante tais constatações, percebe-se que a notificação compulsória configura-se como um dado de extrema relevância para dimensionar a magnitude da violência doméstica no Brasil. Nesta perspectiva, em 2006 foi implantado o Sistema de Vigilância de Violências e Acidentes (Viva) com o propósito de coletar dados e gerar informações relacionadas a violências e acidentes a fim de subsidiar políticas em saúde pública direcionadas a estes agravos, buscando preveni-los. Dentre as informações obtidas por esse sistema, destaca-se a violência doméstica, sexual e ou outras violências registradas no Viva/Sinan que crianças em todo o país são vítimas (BRASIL, 2013).

A notificação da violência além de possibilitar o conhecimento dos casos pelos órgãos responsáveis por intervir junto às famílias, permite a criação de novas estratégias para proteger a criança e romper com o ciclo da violência (FARAJ et al., 2016). Estimativas internacionais revelam que o número de casos de crianças vítimas de algum tipo de violência doméstica tem alta prevalência e incidência (FINKELHOR et al., 2013). As estatísticas nacionais também revelam que o quadro de violência infantil se mostra grave, pois representa $16 \%$ dos casos de violência 
notificados no Sinan (Sistema de Informação de Agravos de Notificação) (SINIMBU et al., 2016).

A fim de proporcionar amparo à criança vitimizada, faz-se necessário repensar como a violência doméstica pode estar atrelada a outras variáveis do contexto familiar, ou seja, quais condições de vulnerabilidade biopsicossocial ocorrem paralelamente à situação de violência, se está sozinha ou interligada a outras situações de risco psicossocial que funcionam como base para sua manifestação. Essa consideração faz-se necessária, pois, segundo Apostólico et al. (2012), é preciso conhecer a realidade a qual a criança e sua família estão inseridas, ter um olhar coletivo sobre a situação de violência parental, para que seja possível propor intervenções de acordo com a demanda existente e contribuir para uma clara e ampla compreensão do processo de saúde. Portanto, o objetivo deste artigo foi refletir sobre o impacto da violência doméstica ao desenvolvimento infantil e analisar de que forma o cuidado familiar e as ações do governo podem atuar como medidas de proteção e promoção da saúde e bem-estar da criança.

O presente trabalho se caracteriza como um estudo teórico da literatura. As fontes de consulta foram livros, periódicos e artigos científicos, selecionados por meio de bases de dados eletrônicas, como: LILACS, Scielo e BVS-PSI, e bibliotecas universitárias. Procedeu-se à seleção dos artigos a partir dos descritores: violência doméstica, violência infantil, risco psicossocial, saúde da criança, cuidado familiar e cuidado social.

Com base nos dados coletados por meio da análise dos artigos, os resultados serão apresentados em quatro categorias: condições de risco à propagação da violência doméstica e vulnerabilidade da criança; a saúde e o desenvolvimento da criança vitimizada; o cuidado familiar e social na promoção da saúde e bem-estar da criança; e a atuação social do estado junto às crianças vitimizadas. A primeira contemplou as condições de risco à propagação da violência doméstica, de forma a entender as adversidades associadas à vivência da família. Em seguida, foram abordadas as condições de saúde e desenvolvimentais da criança vitimizada, a fim de conhecer o perfil delas e quais as possíveis consequências da violência para o seu crescimento. A terceira categoria abordou como o cuidado familiar e social podem favorecer a promoção da saúde e bem-estar da criança e, por fim, buscou-se conhecer quais as propostas de intervenção e serviços ofertados pelo Estado a essas famílias em que a violência é vivenciada.

\section{CONDIÇÕES DE RISCO À PROPAGAÇÃO DA VIOLÊNCIA DOMÉSTICA E VULNERABILIDADE DA CRIANÇA}

A infância é um período no qual a criança vivencia diversos eventos estressores e que podem afetar seu desenvolvimento saudável. Dentre as situações, destacam-se as condições de vulnerabilidade e risco psicossocial que perpassam o cotidiano de crianças. A expressão risco psicossocial refere-se à presença de eventos e circunstâncias sociais que interferem no bem-estar da criança e da família e, consequentemente, limitam a capacidade adaptativa a eventos futuros (MARTURANO, 1997; MILANI; LOUREIRO, 2008).

A violência contra a criança indica que a proteção que deveria ser propiciada pela família tem sido negligenciada, demonstrando a vulnerabilidade dessa em relação aos adultos (MARTINS et al., 2013). O fato da criança depender da relação com o adulto para que consiga crescer já a coloca em condição de vulnerabilidade, pois necessita da ação de seus responsáveis para que seus direitos sejam assegurados. Destacam-se como principais fatores de vulnerabilidade às crianças, 
os riscos inerentes ao contexto familiar relacionados ao alcoolismo, conflitos dos pais e as diferentes formas de violência doméstica, bem como as condições de moradia que expõem a criança a situações de marginalidade, precariedade da oferta de serviços públicos e residências próximas a pontos de tráfico de drogas. Existe uma relação entre vulnerabilidade e os fatores de risco, pois podem ser decorrentes de problemas familiares, escolares, sociais do bairro, uma vez que a criança recebe influência dos diferentes ambientes sociais nos quais está inserida (SIERRA; MESQUITA, 2006).

Dentre as condições adversas presentes no cotidiano de famílias em que a violência doméstica é vivenciada, estudos mostram o uso de álcool ou de outras drogas por parte do agressor, pois a utilização dessas substâncias caracteriza-se como fator desencadeante ou facilitador. Além disso, a situação de desemprego dos responsáveis e a baixa renda são características comuns a essas famílias e evidenciam uma correlação entre violência doméstica e condições precárias de vida (HILDEBRAND et al., 2015; PINTO JUNIOR et al., 2015).

Embora os estudos revelem a correlação entre violência doméstica e condições precárias de vida, não se pode afirmar que a violência infantil se dá apenas em famílias com baixa renda. É certo que a situação pode contribuir para a manifestação da violência, porém não é uma regra. Todavia é necessário questionar por que na maioria das vezes a violência encontra-se associada a esse quadro. Segundo Hildebrand et al. (2015), o trabalho além de fortalecer a autoestima e o sentimento de autoeficácia dos responsáveis, proporciona melhores condições de vida à família. Nota-se que o trabalho fornece à família mais que suporte financeiro, possibilita o sentimento de bem-estar.

No que se refere ao perfil das crianças vítimas de violência doméstica, verificou-se que a maioria é do sexo feminino. Dentre as possíveis explicações, destacam-se os fatores históricos e culturais referentes à desigualdade de gênero, que impelem ao abuso e exploração de meninas. Embora nos dias atuais a mulher tenha conquistado seu espaço no mercado de trabalho, sua figura ainda é vista como frágil e vulnerável, devido a questões culturais que distingue os papéis do homem e da mulher (MARTINS et al., 2013; PINTO JUNIOR et al., 2015).

Nota-se que a cultura também influencia a perpetuação da violência física, que na maioria das vezes é justificada pelos agressores como uma prática educativa. $\mathrm{O}$ argumento é reforçado pela sociedade como forma de corrigir e exortar a criança. Essa situação torna possível a reflexão de que se faz necessário o estímulo a novas formas de educar, que sejam menos danosas e mais eficazes, sem que tenha a necessidade do uso da violência para isso (ALMEIDA et al., 2013). Segundo Martins et al. (2013), a apropriação da violência por parte dos pais como uma medida disciplinadora constitui-se, muitas vezes, uma reprodução de comportamentos dos quais já foram vítimas quando crianças e adolescentes.

É preciso romper com o estigma que permeia a cultura brasileira de que a punição física é uma forma para educar. Essa crença torna ainda mais difícil romper com o hábito passado de geração para geração, o qual contribui para a perpetuação da violência infantil. A prevenção da violência contra a criança está diretamente relacionada às mudanças das representações sociais na sociedade, uma vez que influenciam os hábitos e comportamentos ante aos fenômenos sociais (BRANCO; TOMANIK, 2012).

Segundo Correa (2007), nos casos de violência familiar geralmente a história de vida dos pais traz abandonos, castigos e abusos que não foram elaborados e pensados, e são transmitidos e repetidos inconscientemente pelas próximas 
gerações. Pais que não foram acolhidos em sua dor psíquica quando crianças repetem o comportamento quando adultos de forma inconsciente, sem ter a percepção do ciclo da violência. Soma-se ao fator psíquico, a influência do componente social em que a violência física é reforçada por ser reconhecida culturalmente como uma prática educativa, mas que na verdade simboliza a dificuldade que os próprios pais vitimizados têm de pensar sua dor e, como consequência, utilizam a força como medida de correção na tentativa de reprimir qualquer possibilidade de entrar em contato com o trauma não elaborado.

Além dos fatores adversos relacionados à própria dinâmica familiar ou condições sociais, outro aspecto que predispõe a criança a maior vulnerabilidade refere-se à denúncia dos maus-tratos, pois requer que adultos estejam atentos aos sinais de violência sofridos. Mais uma vez evidencia-se a fragilidade da criança, pois a busca por auxílio não depende de seus esforços, mas do olhar e cuidado do outro. Com base nesta premissa, Branco e Tomanik (2012) alertam para a necessidade de que profissionais da área da educação e da saúde estejam sensíveis para perceber os sinais ou indícios de violência, pois podem ser os únicos contatos que a criança tem além do seu ambiente familiar.

\section{A SAÚDE E O DESENVOLVIMENTO DA CRIANÇA VITIMIZADA}

A violência doméstica vivenciada pela criança constitui uma realidade dolorosa, pois revela maus-tratos que permeiam o contexto familiar e prejuízos pessoais a curto, médio e longo prazo, os quais afetam seu desenvolvimento físico e psicossocial. As consequências desse tipo de violência podem ser devastadoras para o engajamento da criança na sociedade, uma vez que as experiências vivenciadas na infância influenciam na vida adulta (RAMOS; SILVA, 2011).

Os prejuízos derivados da violência doméstica contra a criança comprometem sua saúde física e mental, pois afetam seu desenvolvimento biológico, emocional e cognitivo, e podem ocasionar a manifestação de transtornos mentais. A violência familiar é um fenômeno complexo que abrange questões relacionadas à agressividade no ser humano e suscita reflexões acerca de suas causas e consequências para o desenvolvimento das vítimas (BARROS; FREITAS, 2015; HILDEBRAND et al., 2015).

Em um estudo realizado por Hildebrand et al. (2015), cujo objetivo foi avaliar os possíveis problemas de saúde mental em crianças e adolescentes vítimas de violência doméstica, atendidos em um serviço de saúde, constatou-se como sintomas mais frequentes os problemas de conduta, de atenção, concentração e hiperatividade. Dentre as dificuldades emocionais, salientam-se indicadores de depressão e ansiedade, como déficits nos relacionamentos interpessoais.

Segundo Cunha e Borges (2013), a vivência da violência doméstica por crianças pode desencadear o Transtorno de Estresse Pós-Traumático, que surge após a exposição a um evento traumático, vivenciado ou testemunhado, responsável por desencadear sintomas de medo intenso e impotência. Dessa forma, o fato da criança vitimizada vivenciar situações traumáticas advindas da violência torna-a vulnerável ao desenvolvimento desse tipo de transtorno. Sua manifestação também pode ser associada a comorbidades, como transtornos do humor, de ansiedade, de déficit de atenção (TDA) e de comportamento disruptivo (TDACD).

Gomez e Bazon (2014) em um estudo que objetivou determinar a presença de indicadores de maus-tratos infantis e sua associação com problemas emocionais e comportamentais, verificaram que as crianças vítimas de violência doméstica são propensas a apresentarem sintomas de depressão e ansiedade, e a manifestar 
dificuldade em tarefas comuns à fase do desenvolvimento, como a adaptação ao meio escolar. Segundo Bolsoni-Silva et al. (2016), práticas parentais negativas como gritar ou agredir a criança, podem contribuir para a manifestação de dificuldades comportamentais internalizantes, que se caracterizam por sintomas de ansiedade, retraimento, depressão e sentimento de inferioridade.

Preto e Moreira (2012) realizaram uma pesquisa a fim de avaliar as repercussões da violência doméstica contra mulheres na aprendizagem escolar de seus filhos. Participaram do estudo crianças e adolescentes, dos quais 50 eram filhos de mulheres vítimas de violência doméstica e 50 filhos de mulheres não vítimas de violência doméstica. Os resultados revelaram que a exposição à violência doméstica afeta negativamente $\mathrm{o}$ desenvolvimento da autorregulação $\mathrm{e} o$ rendimento acadêmico da criança. Na mesma perspectiva, Spiller et al. (2012), em um estudo que buscou examinar se a violência vivenciada por mulheres está associada aos problemas de comportamento disruptivo de seus filhos, verificaram que havia uma associação positiva entre a vitimização das mães e as dificuldades comportamentais da criança.

Maldonado e Williams (2005), em uma pesquisa que estudou o comportamento agressivo de crianças do sexo masculino na escola e sua relação com a violência doméstica, verificaram que as crianças expostas a esse tipo de violência apresentavam alto índice de comportamento agressivo no ambiente escolar. Segundo os autores, as dificuldades comportamentais da criança expressadas por meio de atitudes agressivas podem ser entendidas como um "pedido de ajuda" da vítima que está em condições de risco psicossocial.

Milani e Loureiro (2009), em um estudo que objetivou avaliar crianças com história de risco psicossocial associado à violência doméstica, e compará-las com um grupo de crianças sem histórico de risco, quanto ao autoconceito e ao desempenho escolar, verificaram que as crianças vítimas de violência doméstica apresentam mais dificuldade no desempenho acadêmico na área de escrita. Os resultados também revelaram que essas crianças apresentam prejuízos no autoconceito. As crianças vítimas de violência doméstica julgam-se culpadas pelos eventos negativos que acontecem no seu cotidiano, pois relacionam as situações com algo interno. As autoras também constataram que as crianças vítimas de violência apresentam sinais de comprometimento em áreas relacionadas à socialização e ao desempenho acadêmico. A partir dessas considerações, pode-se inferir que tais crianças não contam com recursos internos necessários para enfrentarem as dificuldades desenvolvimentais que a idade escolar exige, configurando-se em uma situação de vulnerabilidade, diante a tarefa de produtividade que é esperada da criança nesta fase da vida.

Segundo Loos e Cassemiro (2010), algumas práticas parentais configuram-se como fatores de risco para o desenvolvimento infantil. Dentre as práticas, destacamse a punição física, relacionamento conflituoso dos pais, ausência de monitoria e regras inconstantes. Para os autores, o autoconceito e a autoestima de crianças estão associados ao relacionamento conjugal harmonioso de seus genitores, demonstrações de afeto e regras, reforçamento positivo e comunicação. Os resultados do estudo revelam que as práticas parentais positivas e o envolvimento familiar saudável possibilitam à criança condições para desenvolver sentimentos de competência, bem-estar geral e bom aproveitamento escolar.

Além das punições físicas, a violência contra a criança pode ser constatada por outros indicadores de maus-tratos. Dentre os indicadores, destaca-se o tempo excessivo de demora para a primeira consulta ao pediatra, o não comparecimento à 
consulta de retorno, o atraso de vacinas e a desnutrição, que podem evidenciar um quadro de negligência (SANTOS et al., 2009).

Nessa perspectiva, Pasian et al. (2015) realizaram um estudo que objetivou descrever a utilização do Child Neglect Index, como um instrumento para identificar casos de crianças negligenciadas por seus pais/cuidadores no contexto brasileiro. Os dados obtidos evidenciaram que as crianças vítimas de negligência apresentam indicadores relacionados à falta de supervisão parental no que se refere a cuidados com alimentação, vestimenta, higiene, saúde física, saúde mental e educação.

É importante ressaltar que a violência contra a criança pode se manifestar por meio de outros indicadores de maus-tratos, além das punições físicas, como por exemplo, a negligência. Segundo Pasian et al. (2013), considera-se como negligência quando os pais, de modo crônico, não possuem disposição ou capacidade psicológica necessária para realizar os cuidados à criança, e, por sua vez, acabam por responder inadequadamente às demandas de seus filhos. Crianças vítimas de negligência apresentam indicadores relacionados à falta de supervisão parental no que se refere a cuidados com alimentação, vestimenta, higiene, saúde física, saúde mental e educação.

A negligência se manifesta pela falta de empenho do adulto para com o cuidado diário e necessário à criança, que omite atos de proteção e educação, como: não alimentá-la corretamente, não medicá-la quando necessário, não mantêla com a mínima higiene, não educar e nem impor limites, não mandar à escola. Nota-se que a negligência à criança vai além das suas necessidades físicas, mas envolve a omissão de práticas educativas necessárias a essa fase (BACKES, 1999).

Em um estudo realizado por Maciel et al. (2010), cujo objetivo foi avaliar as estratégias de promoção da saúde realizadas pelo enfermeiro no ambiente escolar de um Centro Municipal de Educação Infantil e analisar o perfil das crianças atendidas, constatou-se que alguns alunos vivenciavam situações de violência doméstica e negligência familiar. De uma amostra de 350 crianças atendidas 4,6\% estavam desnutridas, $6,4 \%$ apresentavam risco nutricional e $80 \%$ apresentavam uma higiene bucal inadequada, evidenciada pela presença de cáries. As crianças que se encontravam em risco de desnutrição foram encaminhadas à unidade de saúde do território. A maioria dos pais ao serem indagados sobre o motivo de não levarem a criança ao serviço de saúde, justificou-se pela falta de tempo, pois o serviço funciona durante a jornada de trabalho e sua ida à unidade de saúde resultaria na perda de um dia de trabalho.

\section{O CUIDADO FAMILIAR E SOCIAL NA PROMOÇÃO DA SAÚDE E BEM- ESTAR DA CRIANÇA}

A família é o primeiro agrupamento ao qual a criança está inserida, e o que mais influencia a formação de sua personalidade. É preciso indagar sobre as responsabilidades da família como ambiente primário para a constituição de um novo ser, a fim de orientá-la no seu papel como promotora do crescimento e amadurecimento saudável da criança. O desenvolvimento infantil saudável está interligado à vinculação satisfatória nas relações familiares, ou seja, depende do relacionamento construído entre pais e filhos (FERREIRA et al., 2016).

Nesta perspectiva, o empoderamento dos pais no cuidado dos filhos nos processos educacionais, disciplinares e vinculares torna-se essencial e indispensável, já que proporciona o desenvolvimento de aspectos relativos à empatia, autoestima, consciência moral e ética, e consequentemente, favorece a promoção da saúde e bem-estar da criança. O empoderamento dos pais ocorre 
quando diante de um erro dos filhos, os auxiliam a introjetar a instância da disciplina, pois a educação não consiste em um mero discurso, mas em um modo de ser que inspira à criança autoconfiança e the proporciona segurança de que é amada, mesmo quando é repreendida (FERREIRA et al., 2016).

Para que os direitos da criança sejam assegurados, elas dependem, em sua maioria, dos deveres dos adultos. Por isso, a criança é percebida como vítima, pois ainda não possui autonomia e independência para a busca de seu próprio bem e efetivação de seus direitos, o que a deixa em condição de vulnerabilidade. Cabe à família, à sociedade e ao Estado a obrigação de responder por sua formação, ou seja, de se responsabilizar pelo seu crescimento e desenvolvimento. Desta forma, constata-se a necessidade de investimentos que visem à redução das condições de vulnerabilidade que possam interferir na qualidade de vida e bem-estar do público infantil (SIERRA; MESQUITA, 2006).

A aparência de bem-estar é um índice de cidadania. Quando as crianças estão destituídas dessas condições, dificilmente serão consideradas como sujeitos de direitos. Se a criança não tem seus direitos assegurados, torna-se ainda mais vulnerável, pois seus relacionamentos serão constituídos a partir da percepção de que não os possuem (SIERRA; MESQUITA, 2006). A criança se vê excluída e marginalizada por não usufruir dos mesmos direitos vividos por outros, o que a fragiliza ainda mais.

Branco e Tomanik (2012) ao considerarem que a prevenção da violência doméstica infantil está relacionada à mudança das representações sociais que esta tem na sociedade, afirmam ser importante o trabalho comunitário junto às famílias e o estabelecimento de políticas públicas de enfrentamento à violência. O trabalho comunitário, ao aproximar-se dessas famílias no contexto social cotidiano, torna possível o conhecimento da realidade que as circunda e possibilita a reflexão sobre as relações intrafamiliares e o suporte para a criação de novas formas de relacionamento, que não envolvam ações de violência. Nesta mesma perspectiva, Régio et al (2015) afirmam que a prevenção da violência infantil está relacionada a produção e a reprodução de conhecimentos científicos obtidos a partir de estudos sociais, e esses, por sua vez, devem abranger as representações subjetivas e culturais que promovem a conquista dos direitos de cidadania na tentativa de amparar a criança vitimizada.

Na mesma visão, Pinto Junior et al. (2015) discorrem que o enfrentamento da violência doméstica contra a criança é uma tarefa difícil, pois, como já se comentou, esbarra em questões complexas acerca da noção de família e de infância construídas ao longo da história. As concepções e representações errôneas sobre o fenômeno dificultam a identificação, notificação e prevenção. Por isso, as ações que objetivam a discussão dessas questões com a população que se encontra mais vulnerável e exposta a condições de risco são promissoras, pois podem efetivar o fortalecimento de políticas de assistência à criança, que visem a formação de uma cultura fundamentada na educação familiar não violenta. Para Sierra e Mesquita (2006), não se trata apenas de mudar o olhar do adulto sobre a criança, mas da necessidade de intervir para modificar a situação e favorecer a ela melhores condições de vida.

\section{A ATUAÇÃO SOCIAL DO ESTADO JUNTO ÀS CRIANÇAS VITIMIZADAS}

Diariamente, crianças são vítimas de algum tipo de violência em seu próprio ambiente, protagonizada por pessoas muito próximas de sua rede afetiva e social. A violência infantil é um fenômeno social e histórico que abrange aspectos 
psicossociais e um caráter dinâmico de interação familiar, cultural e social. Por esse motivo, é considerada um problema social e de saúde pública (BARROS; FREITAS, 2015).

Nota-se que o Estado dispõe de alguns serviços na tentativa de intervir junto às famílias em que a violência contra a criança é perpetrada, como a rede de cuidados a partir da Estratégia de Saúde da família da qual fazem parte órgãos como Conselho de Direitos da Criança e do Adolescente, Conselho Tutelar, Ministério Público e o NASF (XIMENES NETO et al., 2013). Embora os serviços visem prestar atendimento e acompanhamento às crianças vítimas de violência, nota-se que ainda há uma lacuna quanto à prevenção e intervenção imediata desses programas.

O setor de saúde sempre teve a atenção voltada para o atendimento de vítimas de violência, porém, poucas eram as tentativas de estudo e planejamento de intervenções que visassem a prevenção do fenômeno. A mudança de enfoque, do modelo curativo para o preventivo é recente, pautada nas ideias de proteção e promoção da saúde, que visam ampliar a noção de bem-estar individual e coletivo. Nesta perspectiva, a Política de Promoção da Saúde possui um tópico específico para a prevenção da violência e estímulo à cultura de paz, com a finalidade de contribuir para a ampliação e fortalecimento da rede Nacional de Prevenção e para o incentivo e monitoramento dos Planos Estaduais e Municipais de prevenção da violência, investir na capacitação dos gestores e profissionais da área da saúde e educação visando a identificação e encaminhamento adequado de situações de violência doméstica, a implementação da ficha de notificação de violência interpessoal e a implantação de Serviços Sentinela que visem complementar o sistema de informações existente para a vigilância de violências, assim como o estímulo à articulação intersetorial (SIQUEIRA et al., 2013).

Portanto, faz-se necessário capacitar os profissionais de saúde e educação para lidarem com as situações de violência doméstica, visando a resolução de conflitos e ampliação da capacidade de comunicação e diálogo a fim de atuarem na prevenção. Mediante tais considerações, nota-se que é preciso capacitar os profissionais para criar novas estratégias que abordem a problemática, considerando os conflitos existentes na relação criança-família, com o propósito de envolver todos esses sujeitos na construção de uma cultura de paz (SIQUEIRA et al., 2013).

Uma cultura de paz fundamentada essencialmente nos seguintes valores e princípios: no respeito à vida, no fim da violência, na promoção e prática da nãoviolência por meio da educação, do diálogo e da cooperação. Entretanto, é preciso um trabalho interligado à rede de proteção aos direitos da criança e do adolescente para que se tenha a identificação, notificação, promoção e recuperação das vítimas de violência. A estratégia possibilitaria uma parceria na prevenção contra a violência doméstica (SIQUEIRA et al., 2013).

Vale ressaltar que o atendimento e a proteção aos indivíduos que sofreram algum tipo de violência doméstica e, consequentemente, tiveram seus direitos violados, estão sob a responsabilidade do Ministério de Desenvolvimento Social e Combate à Fome. De acordo com a implantação do Sistema Único de Assistência Social (SUAS), em 2003, os serviços socioassistenciais oferecidos pelo governo passaram a ser classificados em duas categorias: Proteção Social Básica, que visa a prevenção, e a Proteção Social Especial, que objetiva a proteção (BRASIL, 2005; BRASIL, 2010).

A Proteção Social Básica trabalha com famílias em condição de vulnerabilidade social, privação, pobreza, fragilização de vínculos afetivos, 
relacionais e de pertencimento social. Seu objetivo é a prevenção de risco por meio do desenvolvimento de potencialidade, aquisições, fortalecimento dos vínculos familiares e comunitários. Esse serviço é realizado pelo CRAS (Centros de Referência de Assistência Social) (BRASIL, 2005; BRASIL, 2010). Quando a demanda existente apresenta um grau de complexidade maior, encaminham-se os casos para outro nível de proteção.

A Proteção Social Especial entra em cena, por atuar em casos que houve violação de direitos e/ou rompimento dos vínculos afetivos e comunitários. Esse tipo de serviço é prestado à população que vive em condição de risco psicossocial, como consequência de maus-tratos físicos, psíquicos, abuso sexual, abandono, uso de substâncias psicoativas, cumprimento de medidas socioeducativas, condição de rua, situação de trabalho infantil, entre outras. O acompanhamento nesses casos é realizado pelos CREAS (Centro de Referência Especializado de Assistência Social) (BRASIL, 2005; BRASIL, 2010).

Os serviços realizados pela Proteção Social Especial são classificados em: Média Complexidade e Alta Complexidade. Os de Média Complexidade ofertam atendimentos às famílias e sujeitos que vivenciam/vivenciaram situações de violação de direitos e que ainda apresentam vínculos comunitários e afetivos preservados. Esse tipo de serviço necessita de mais estrutura que possibilite atendimento especializado e acompanhamento sistemático e monitorado. Enquanto que os de Alta Complexidade oferecem proteção integral (moradia, higienização e trabalho protegido), pois são dirigidos às famílias e indivíduos em situação de ameaça e que nessas condições precisam ser retirados de seu núcleo familiar e, ou, comunitário (BRASIL, 2005; BRASIL, 2010).

O CREAS (Centro de Referência Especializado de Assistência Social) tratase de um órgão público que atua em casos em que houve a violação de direitos. $O$ serviço é ofertado à população que vive em condição de risco psicossocial, como consequência de maus-tratos físicos, psíquicos, abuso sexual, abandono, uso de substâncias psicoativas, cumprimento de medidas socioeducativas, condição de rua e situação de trabalho infantil (BRASIL, 2010).

Nota-se que o CREAS surgiu com o intuito de amparar as vítimas de violência e intervir junto à família na tentativa de romper com esse ciclo e, consequentemente, propiciar melhores condições de vida. Porém, embora haja esforço por parte do Estado, essas famílias, em sua maioria, se encontram em condição de risco psicossocial e possuem déficits quanto a seu bem-estar e qualidade de vida. Estudos mostram que embora as crianças e famílias em que a violência foi vivenciada sejam acompanhadas por serviços socioassistenciais, as intervenções realizadas não parecem satisfatórias para romper com a violência e proporcionar uma rede de proteção às vítimas (HILDEBRAND et al., 2015; PINTO JUNIOR et al., 2015).

Segundo Hildebrand et al. (2015), ainda há uma lacuna a ser preenchida pela Rede de Proteção à criança vitimizada, pois devido à ausência na efetividade das políticas públicas de atendimento, as famílias que frequentam esses serviços apresentam alto índice de problemas de saúde mental. Pode-se inferir que, apesar dessas famílias estarem sendo acompanhadas por profissionais das diversas áreas, existe a necessidade de refletir acerca de estratégias metodológicas mais efetivas.

Embora os serviços sejam ofertados pelo governo na tentativa de intervir na situação de violência, é preciso reconhecer que cada família possui sua singularidade, sua própria dinâmica. Segundo Osório e Valle (2002), um grupo familiar tem suas próprias leis inerentes a seu funcionamento e cada membro possui 
sua singularidade, porém todos exercem uma ação interativa com objetivos compartilhados. Nesta perspectiva, é preciso questionar se as estratégias de intervenção junto às famílias consideram a autonomia e a singularidade de cada uma e de cada membro envolvido.

\section{CONSIDERAÇÕES FINAIS}

O objetivo deste estudo foi refletir sobre o impacto da violência doméstica ao desenvolvimento infantil e analisar de que form o cuidado familiar e as ações do governo podem atuar como medidas de proteção e promoção da saúde e bem-estar da criança. Com base nos artigos analisados, verificou-se que a violência vivenciada pela criança geralmente encontra-se associada a fatores adversos que envolvem condições precárias de vida, como desemprego e baixa renda, como o uso de álcool e outras drogas pelos pais. Além desses aspectos, nota-se que a propagação da violência muitas vezes se vê amparada pelo contexto cultural, que incentiva a punição física como método educativo. Nesta perspectiva, percebe-se que o ciclo da violência está amparado em fatores econômicos, sociais, psicológicos e culturais, sendo necessárias não somente intervenções que proporcionem melhores condições de vida a essas famílias, mas que possibilitem o rompimento com as representações sociais que a sociedade atual tem sobre a violência.

Os estudos analisados indicaram prejuízos ao desenvolvimento físico, emocional e cognitivo das crianças que sofrem a violência doméstica. Notou-se que a violência pode afetar o engajamento social, o desempenho acadêmico e a capacidade adaptativa da criança face às demandas do processo de desenvolvimento, afetando a qualidade de vida e bem-estar. Uma família permeada pela violência nega à criança não somente condições para um desenvolvimento biológico saudável, mas também as condições básicas para seu desenvolvimento social.

A família por ser o primeiro agrupamento social da criança, exerce papel fundamental em sua formação. Porém nas famílias em que a violência infantil é perpetrada os vínculos encontram-se prejudicados. É preciso um olhar social que não discrimine essa família, mas que a compreenda em seus determinantes histórico-sociais e se sensibilize perante a realidade vivenciada por ela, na tentativa de orientá-la na retomada do cuidado à criança. As ações do Estado devem estar em consonância com esse ideal, estimulando intervenções que envolvam todos os sujeitos em busca de uma cultura da paz e sobretudo de respeito ao próximo.

Dentre as limitações deste estudo, destaca-se a carência de pesquisas que valorizem a autopercepção da criança e da família sobre a vivência da violência. Os estudos analisados em sua maioria apresentam uma abordagem diagnóstica sobre as consequências da violência para o desenvolvimento infantil e as condições de vida que circundam a família. Faz-se necessário o desenvolvimento de estudos que abordem a subjetividade dessa criança, que se atentem para o fato de que é um ser repleto de vontades e desejos, que possui seus direitos, e que também tem capacidade para expressar sua percepção sobre sua vivência. Pesquisas realizadas neste âmbito podem contribuir para estimular o olhar da sociedade sobre a criança, considerando-a um ser dotado de sentimentos, resgatando-a da condição de vítima que pouco diz a respeito de sua subjetividade. Novas pesquisas desenvolvidas a partir da autoexpressão da família e da criança vitimizada podem contribuir para o resgate destes sujeitos que muitas vezes encontram-se escondidos no estigma da violência, negligenciados em sua dimensão subjetiva. 


\section{REFERÊNCIAS}

ALMEIDA, A. A., MIRANDA, O. B., \& FREITAS, M. L. Violência doméstica/intrafamiliar contra crianças e adolescentes: uma revisão bibliométrica. Gerais: Revista Interinstitucional de Psicologia, 6(2), 298-311, 2013. Disponível em: http://pepsic.bvsalud.org/pdf/gerais/v6n2/v6n2a11.pdf.

APOSTÓlICO, M. R., NÓBREGA, C. R., GUEDES, R. N., FONSECA, R. M. G. S., \& EGRY, E. Y. Características da violência contra a criança em uma capital brasileira. Revista Latino-Americana de Enfermagem, 20(2), 266-73, 2012. doi: 10.1590/S0104-11692012000200008

BACKES, D. L. Indicadores de maus-tratos em crianças e adolescentes para uso na prática de enfermagem. Porto Alegre: Escola de Enfermagem da Universidade Federal do Rio Grande do Sul, 1999.

BARROS, A. S., \& FREITAS, M. F. Q. Violência doméstica contra crianças e adolescentes: consequências e estratégias de prevenção com pais agressores. Pensando famílias, 19(2), 102-114, 2015. Disponível em: http://pepsic.bvsalud.org/pdf/penf/v19n2/v19n2a09.pdf.

BRASIL. Ministério do Desenvolvimento Social e Combate à Fome, Secretaria Nacional de Assistência Social. Sistema Único de Assistência Social (SUAS, Norma Operacional Básica (NOB/SUAS) - Construindo as Bases para a implantação do Sistema Único de Assistência Social. Brasília: Editora do Ministério da Saúde. 2005.

BRASIL. Ministério do Desenvolvimento Social e Combate à Fome. Secretaria Nacional de Assistência Social. Sistema Único de Assistência Social (SUAS): Manual informativo para jornalistas, gestores e técnicos Básica. Brasília: Editora do Ministério da Saúde. 2010.

BRASIL, Ministério do Desenvolvimento Social e Combate à Fome. (2010). Sistema Único de Assistência Social (SUAS): Manual informativo para jornalistas, gestores e técnicos. Brasília, DF: Editora do Ministério da Saúde. Recuperado em http:// www.mds.gov.br/assistenciasocial/secretaria-nacional-deassistencia-socialsnas/guias/sistema-unico-de-assistenciasocial-suas-manual-informativo-parajornalistas-gestores-etecnicos/sistema-unico-de-assistencia-social-suasmanualinformativo-para-jornalistas-gestores-e-tecnicos.

BOLSONI-SILVA, A. T., LOUREIRO, S. R., \& MARTURANO, E. M. Comportamentos internalizantes: associações com habilidades sociais, práticas educativas, recursos do ambiente familiar e depressão materna. Psicologia (Porto Alegre), 47(2), 111120, 2016. doi: 10.15448/1980-8623.2016.2.20806.

BRANCO, M. A. O., \& TOMANIK, E. A. Violência doméstica contra crianças e adolescentes: prevenção e enfrentamento. Psicologia e Sociedade, 24(2), 402-411, 2012. doi: 10.1590/S0102-71822012000200018.

BRASIL. Ministério da Saúde (MS). Viva: vigilância de violências e acidentes, 2009, 2010 e 2011. Brasília: MS; 2013. 
CORREA, O. B. R. O transgeracional na violência intrafamiliar. In O. B. R. Correa (Org.). Grupo familiar e psicanálise: ressonâncias clínicas (p. 53-67). São Paulo: Vetor, 2007.

CUNHA, M. P., \& BORGES, L. M. Transtorno de Estresse Pós-Traumático (TEPT) na infância e na adolescência e sua relação com a violência familiar. Boletim Academia Paulista de Psicologia,33(85), 312-329, 2013. Disponível em: <http://pepsic.bvsalud.org/scielo.php?script=sci_arttext\&pid=S1415-

711X2013000200008\&lng=pt\&nrm=iso

DAY, V. P., TELLES, L. E. B., ZORATTO, P. H., AZAMBUJA, M. R. F., MACHADO, D. A., SILVEIRA, M. B., DEBIAGGI, M., REIS, M. G., CARDOSO, R. G., \& BLANK, $P$. Violência doméstica e suas diferentes manifestações. Revista psiquiátrica do Rio Grande do Sul, Porto Alegre, v. 25, supl. 1, p. 9-21, 2003. Doi: 10.1590/S0101-81082003000400003

FARAJ, S. P., SIQUEIRA, A. C., \& ARPINI, D. M. Notificação da Violência: Percepções de Operadores do Direito e Conselheiros Tutelares. Psicologia: Ciência e Profissão, 36(4), 907-920, 2016. doi: 10.1590/1982-3703000622014.

FERREIRA, S. M., BOREGAS, F. C. B., GREINERT, B. R. M., CORTEZ, D. A. G., \& MILANI, R. G. O empoderamento dos pais na educação e nos cuidados dos filhos: contribuições teóricas. Cinergis, 17(3), 239-244, 2016. doi: 10.17058/cinergis.v17i3.8060.

FINKELHOR, D., TURNER, H. A., SHATTUCK, A., \& HAMBY, S. L. Violence, crime, and abuse exposure in a national sample of children and youth: an update. JAMA pediatrics, 167(7), 614-621, 2013. doi: 10.1001/jamapediatrics.2013.42.

GOMEZ, V. R. V., \& BAZON, M. R. Association between child maltreatment indicators and developmental problems in early childhood education. Journal of Human Growth and Development, 24(2), 214-220, 2014.

HILDEBRAND, N. A., CELERI, E. H. R. V., MORCILLO, A. M., \& ZANOLLI, M. L. Violência doméstica e risco para problemas de saúde mental em crianças e adolescentes. Psicologia: Reflexão e Crítica, 28(2), 213-221, 2015. doi: 10.1590/1678-7153.201528201

LOOS, H.; CASSEMIRO, L. F. K. Percepções sobre a qualidade da interação familiar e crenças autorreferenciadas em crianças. Estudos de psicologia(Campinas), Campinas, v. 27, n. 3, p. 293-303, 2010. Doi: 10.1590/S0103-166X2010000300002.

MACIEL, E. L. N., OLIVEIRA, C. B., FRECHIANI, J. M., SALES, C. M. M., BROTTO, L. D. A., \& ARAÚJJO, M. D. Projeto Aprendendo Saúde na Escola: a experiência de repercussões positivas na qualidade de vida e determinantes da saúde de membros de uma comunidade escolar em Vitória, Espírito Santo. Ciência \& saúde coletiva, Rio de Janeiro, v. 15, n. 2, p. 389-396, 2010. Doi:10.1590/S141381232010000200014. 
MALDONADO, D. P. A.; WILLIAMS, L. C. A. O comportamento agressivo de crianças do sexo masculino na escola e sua relação com a violência doméstica. Psicologia em estudo, v. 10, n. 3, p. 353-362, 2005. Doi: 10.1590/S1413-73722005000300003.

MARTINS, A. F., SILVA, K. A., BEZERRA FILHO, J. G., RIBEIRO, M. A., \& QUEIROZ, A. C. M. Violence with children and adolescents: profiles of victims, of aggression and of perpetrators/Violência envolvendo crianças e adolescentes: perfil das vítimas, da agressão e dos agressores. Revista de Enfermagem da UFPI, 2(4), 50-7, 2013. Disponível em: http://www.ojs.ufpi.br/index.php/reufpi/article/view/1219.

MARTURANO, M. A. A criança, o insucesso escolar e a família: condições de resiliência e vulnerabilidade. In. Marturano, E. M., Loureiro, S. R. Zuardi, A. W. (Orgs). Estudos em Saúde Mental. Ribeirão Preto: Comissão de Pós-graduação em Saúde Mental FMRP/USP, 1997. p. 132-145.

MILANI, R. G.; LOUREIRO, S. R. Crianças em risco psicossocial associado à violência doméstica: o desempenho escolar e o autoconceito como condições de proteção. Estudos de Psicologia (Natal), Natal, v. 14, n. 3, p. 191-198, 2009. Doi: 10.1590/S1413-294X2009000300002.

MILANI, R. G., \& LOUREIRO, S. R. Famílias e violência doméstica: condições psicossociais pós ações do conselho tutelar. Psicologia: ciência e profissão, 28(1), 50-67, 2008. Doi: 10.1590/S1414-98932008000100005.

NUNES, A. J., \& SALES, M. C. V. Violência contra crianças no cenário brasileiro. Ciência \& saúde coletiva, 21(3), 871-880, 2016. doi: 10.1590/141381232015213.08182014.

OSORIO, L. C., \& DO VALLE, M. E. Terapia de famílias: novas tendências. Artmed Editora, 2002.

PASIAN, M. S., FALEIROS, J. M., BAZON, M. R., \& LACHARITÉ, C. Negligência infantil: a modalidade mais recorrente de maus-tratos. Pensando familias, 17(2), 61-70, 2013.

PASIAN, M. S., BAZON, M. R., PASIAN, S. R., \& LACHARITÉ, C. Negligência infantil a partir do Child Neglect Index aplicado no Brasil. Psicologia: Reflexão e Crítica, 28(1), 106-115, 2015. doi: 10.1590/1678-7153.201528112.

PINTO JUNIOR, A. A., CASSEPP-BORGES, V., \& DOS SANTOS, J. G. Caracterização da violência doméstica contra crianças e adolescentes e as estratégias interventivas em um município do Estado do Rio de Janeiro, Brasil. Cadernos de Saúde Coletiva, 23(2), 124-131, 2015. doi: 10.1590/1414462X201500020062.

PRETO, M., \& MOREIRA, P. A. S. Auto-regulação da aprendizagem em crianças e adolescentes filhos de vítimas de violência doméstica contra mulheres. Psicologia, Reflexão e Crítica, 25(4), 730-737, 2012. doi: 10.1590/S0102-79722012000400012. 
RAMOS, M. L. C. O., \& SILVA, A. L. Estudo sobre a violência doméstica contra a criança em unidades básicas de saúde do município de São Paulo - Brasil. Saúde e Sociedade, 20(1), 136-146, 2011. doi: 10.1590/S0104-12902011000100016.

RÉGIO, L., EGRY, E. Y., \& APOSTÓLICO, M. R. Consideraciones acerca de la importancia del estudio de saberes necesarios para el afrontamiento de la violencia infantil en la atención primaria de salud. Revista de investigaciones UNAD Bogotá - Colombia, 14(2), 137-149, 2015. Doi: 10.22490/25391887.1463.

SANTOS, S. R., FERREIRA, A. L., PAIXÃO, A. C., PFEIFFER, L. Y., AQUINO, L. A., \& AMARAL, J. J. F. Adaptação e aplicabilidade do componente "maus-tratos" à estratégia da Atenção Integrada às Doenças Prevalentes na Infância no Brasil. Revista Brasileira de Saúde Materno-infantil, Recife, v. 9, n. 3, p. 359366, set. 2009.

SIERRA, V. M., \& MESQUITA, W. A. Vulnerabilidades e Fatores de Risco na Vida de Crianças e Adolescentes. São Paulo em Perspectiva, 20(1), 148-155, 2006. Disponível em: http://produtos.seade.gov.br/produtos/spp/v20n01/v20n01_11.pdf.

SINIMBU, R. B., MASCARENHAS, M. D. M., DA SILVA, M. M. A., DE CARVALHO, M. G. O., DOS SANTOS, M. R., \& FREITAS, M. G. Caracterização das vítimas de violência doméstica, sexual e/ou outras violências no Brasil-2014. Revista Saúde em $\quad$ Foco, $1(1), \quad 2016 . \quad$ Disponível em: https://smsrio.org/revista/index.php/revsf/article/view/199.

SIQUEIRA, C. G., VIEIRA, I. D. \& SANTIAGO, S. R. Domestic violence against children: an analysis from the perspective of parents. Revista de Enfermagem UFPI, 2(1), 49-55, 2013. Disponível em: http://www.ojs.ufpi.br/index.php/reufpi/article/view/830.

SPILLER, L. C., JOURILES, E. N., MCDONALD, R., \& SKOPP, N. A. Physically Abused Women's Experiences of Sexual Victimization and their Children's Disruptive Behavior Problems. Psychol Violence, 2(4), 401-410, 2012. doi: 10.1037/a0028912.

WHO - World Health Organization . Preventing child maltreatment: a guide to taking action and generating evidence. Geneva: WHO; 2006.

XIMENES NETO, F. R. G., SANTOS, M. P. S., SAMPAIO, J. J. C., OLIVEIRA, E. N., CUNHA, I. C. K., \& LEITE, J. L. Análise da produção do cuidado desenvolvido pelo enfermeiro na atenção à criança e ao adolescente vítima de violência doméstica. Sanare, 12(1), 20-26, 2013. Disponível em: https://sanare.emnuvens.com.br/sanare/article/view/324. 